\title{
Research on Negative Influence and Strategies of Multimedia Education in Universities
}

\author{
Ziyan Zhang \\ Information Engineering College \\ Shenyang University \\ Shenyang, Liaoning, P.R.China \\ zzy8814@163.com
}

\author{
Linan Fan \\ Information Engineering College \\ Shenyang University \\ Shenyang, Liaoning, P.R.China \\ linanfan@163.com
}

\begin{abstract}
This paper focuses on misunderstanding and negative effects on multimedia education as well as its usage. Also, the paper provides a degree which should be used in multimedia education, such as encourage teachers' guidance, pay attention to students' feedback, establish teachingaccumulations, as well as choose and produce courseware thoughtfully.
\end{abstract}

Keywords-multimedia education; educational method; educational effects; strategy

\section{INTRODUCTION}

With the increasing usage of multimedia courses and deep-going practice of education, the negative effects are showing after exaggerating e-education functions and ignoring their shortages. Also, by implying multimedia teaching, it can be just a performance with poor qualities of teaching, managing, and courseware levels. The actual effects of them are not satisfied [1]. Facing the teaching evolution in new century, how to use e-teaching systems reasonably is a worthy research for universities. The thesis is trying to figure out strategies and methods from e-teaching negative effects.

\section{CORRECTLY NOTICE AND OBJECTIVELY EVALUATE MULTIMEDIA EDUCATION}

Multimedia computer assistant teaching is a method by utilizing text, graphic, audio, video, animation and other media to produce, transfer and show diversity of non-number data, which is a combination between computer technology and arts presenting. Multimedia technology base on wellillustrated performance provides so many advantages, for example, large information, high interactive, convenient usage, and easy operation. It has been used in so many inclass teaching and provides a new method for education in teaching ideas, contents, measures, models, and procedures. No matter how multimedia technologies are developing, these cannot replace traditional in-class teaching method and the function of teachers. Multimedia education is one of the assistant methods rather than all parts of education.

\section{THE NEGATIVE EFFECTS OF MULTIMEDIA EDUCATION}

In the big wave for e-learning spreading and utilizing in universities, there were some problems and regressive influence which did not attract enough attention[2]. Even though those problems are not caused by multimedia, they were lectures' misunderstandings and misused e-teaching in teaching field.

\section{A. Blindness Used by Multimedia Education}

A lot of universities' lecturers, especially youth teachers, are suffering from the theory of "multimedia is only target". They believe that multimedia is the only way for education and ignore teaching purpose sometimes. If effects of multimedia education are exaggerated, educational rules will be broken which cannot achieve ideal influence of teaching and will against basics of e-teaching.

At present, multimedia teaching is only used for presentation. Some of teachers adopt traditional teaching method by using multimedia technique from "blackboard +chalk" to "screen +keyboard". Basically, this method decreases workloads of lecturers. However, students barely can think or write down notes during class-time since they have to follow teaching speed. They may have impression for some courseware of class, but the main contents or difficulties are hardly remembered for them. In this case, hardly to understand and to review class contents become 2 difficulties. If lack of out-class tutoring, students will have difficulties to obtain knowledge.

A lot of textbooks attach teaching courseware, which designed in each chapter as one teaching unit. This courseware bases on authors' ideas, methods, and experiences. These are hardly fitting into teaching diversity situations. It is also a limitation that those designed courseware cannot be used and be shared between universities flexibly. A current condition is some lecturers adopt the designed courseware without consider their students' status and teaching effects are not ideality.

\section{B. Teaching Method over Formalize}

In one hand, some lecturers are trying to keep pace with modern teaching method or to reduce chalks usage. They just copy all textbooks' contents into Word or PowerPoint. The components are too tedious to attract students. On the other hand, some lecturers pay too much attention to fancy designs of teaching courseware. With some researches on students, they were attracted by new teaching form in the first place. After a while, the more e-teaching involved, the more students were getting bored. Also, some lecturers increase their teaching speed by using courseware and it causes students hardly to understand teaching contents as well as to 
follow lecturers. In the class, multimedia coursewares overstimulate senses of students which restrain their mind activities in deep level and they cannot pay attention to important point. Especially, when knowledge changing and combination of multimedia (audio, text, graphic, and animation), there are a lot of information should be transferred to students in short time. Students barely have time to fully understand and their studying interests reduce dramatically. At the end, e-teaching over-used cause student cannot understand lecture contents, follow teaching speed, accomplish their notes, and obtain nothing after the classes. It is not only un-reaching predicted target, but distributes students' attention, wastes time, and goes against e-teaching basic concept. Currently, multimedia teaching courseware are likely to highly stylized, structure linearization, teaching method fixed, system closed and non-modified, as well as timing unchangeable. All the reasons lead lecturers cannot flexibly adjust teaching contents and ignore real reactions from students. So, teaching media modernization is not equal to teaching optimization.

\section{Weaken Lecturers' leading Role}

In-classing education is a two-way action between lecturers and students. The interaction of both participants is a basic structure of teaching-learning method. The multimedia education is only an assistant tool for lecturers rather than replace lecturers. Some lecturers believe that using e-teaching facilities could increase teaching qualities and they use it in each class. Therefore, multimedia education will be replaced to computer education and shows every program by using computer. In this case, lecturers no longer have the leading roles in the classes and they become computer manipulators or commentators. As a result, education qualities will decline, which create mis-function between humans and computers, students lack of learning interests, and hard to achieve ideal impacts.

\section{The Main Roles of Students Declined}

With the improvement of educational evolution and creation, the main roles of students are received more and more attention. However, there are still a lot of lecturers who adopt old teaching style, or some lecturers utilize modern multimedia teaching method and still insist old teaching style. In this case, teachers play monodrama and students study alone, which lack of interactions between them. Also, to achieve the main role of students should involve all students in order to encourage learning enthusiasm of students.

\section{SEARCHING OPTIMIZED STRATEGY OF MULTIMEDIA EDUCATION}

All the negative effects, which we mention above, cannot be solved in time, the results of multimedia teaching will be influenced and affect educational evolution and talented students training. Therefore, we provide following strategies.

\section{A. Control Multimedia Education Level}

If computers are misusing in educational field, the teaching content will be too simply to attract students or too hard to understand without interactivities. The e-teaching should not follow blindly and not be non-effect. Normally, multimedia teaching is good at the learning contents with dynamic, changeable, and objective forms. Like this, the teaching format can show it priority. Like other contents with strict inference, careful calculation, and emotional influence, these are taught by lecturers directly.

Base on the coursed of current universities, it is undeniable that not all courses are suitable for the teaching method. Some of subjects, with plenty of diagram such as computer basis and mechanism diagram, can take advantages by using computer teaching. Others, with equation inference like mathematics and normal physics, are not suitable for the teaching method. If the e-teaching are forced to over-use, students will lose their concentration and cannot reach the target to improve their abstracted idea or analysis abilities.

\section{B. Reasonable Selecting and Producing Multimedia Courseware}

One of the most important points of multimedia education is a set of good courseware. We need carefully choose and create courseware with following consideration:

1) Shows scientificity, practicability and artistry. Firstly, In-class used courseware select state-compiled textbooks as basic structure. Secondly, teaching syllabuses are used as main axes, which connect different chapters and knowledge points, to insure coherence and cohesion of the courseware. Thirdly, importance and difficulties of teaching contents should be emphasized and make them suit teaching roles and cognitive rules. Lastly, for courseware creation follow the principles of simplicity and practicability to encourage learning interest of students. Also, courseware controlling and switching need direct, convenient, and flexible.

2) Courseware should not contain too much text, in order to become clear and simple. If some knowledge points are hard to understand, they are better used animation, graphics, or tables to explain. Normally, adopting lighten background and darken text receive better vision effects and using opposite method obtain senses of grave or mystery to attract students' attention. Moreover, adding suitable audios will bring activities and get students' attention.

3) Courseware should show characters and a good one must have open functions. Base on students' or different teaching objects provide changeable function (such as modifying and inserting text, audio or animation) in anytime and anywhere. In this case, the impact of courseware will grow and show better level.

\section{Control Teaching Speed, Avoid 'Dyspepsia'}

Teaching speed should be reasonable. When the difficulties and importance are showing on the slides, the lecturers should adopt traditional teaching methods to explain feedbacks from students. At the same time, lecturers provide adequate pause and give some time for students to understand. It is not necessary to present all teaching contents onto the slides. They can save simply questions or content as after-class coursework for students. 


\section{Encourage Lecturers' Main Role}

As a modern teaching method, multimedia education is supporting teaching work, increasing learning effects, breaking learning difficulties, and solving un-solvable problem in traditional education. However, it is only a teaching tool. Human should be considered as the top factor and lecturers are the leading of class activities.

For the lecturers, courseware is a useful assistant. No matter how delicate and advanced the courseware is, these cannot replace the importance of lecturers. The direct communications, guidances, interaction between students and lecturers, they are all irreplaceable by other media. Appropriate explanations, important blackboard-writing, and necessary demonstrations also cannot be achieved by computer. All educational devices or slides are one of the important tools. They need to be controlled by the lecturers. The importance of lecture should be deeply analysis by the lecturers. Sometimes, lecturers should write on blackboard step by step until students understand. Meanwhile, lecturers should notice students understanding or studying level to interactive with them by body language and facial impression. The students will be guided to find, think, and solve problems. The lecturers should interactive with students and encourage them to discovery, exploration, research problems.

\section{E. Pay Attention to the Feedbacks of Students}

Even though educational methods have changed, the roles and the characters of students' development are not altering that they are still the main objects of studying processes. During the processes, students, who respect to receive new knowledge, rely on the processes of themselves to communicate with surroundings, objects conflict with subjects, and experience meet realities. Thus, building students-activity-based in-class mode, courseware is a method of teaching assistance. The participation activities and obtain success happiness are the key of educational accomplishment. How the result will be by using multimedia, students have the voice and the feedbacks of students' knowledge holding are the important measures for educational impacts testing. Therefore, lecturers must pay attention to the communications with students, accept advices and suggestions of students, sum up teaching experiences, improve their teaching ideas, increase courseware qualities, and encourage students to study actively and creatively.

\section{F. Develop Network's Abilities}

The technology of Internet is becoming more and more sophisticated, and extension speed is remarkable. The high speed campus networks provide a bright future for multimedia education. Networking and intelligence fix the disadvantages of in-class e-teaching. Collecting slides and related knowledge to upload Internet, these provide a review method for students as well as a new trend for further study. Lecturers are not necessary to spend too much time to explain in the class. By using Internet, students also can organize their self-study contents, study online, or communicate with other learner and teachers.

\section{G. Establish Teaching Accumulations}

To create educational accumulations to resolve individuation dilemma, we could use accumulations to replace current courseware. The educational accumulations is seeing as source material or fragment of courseware, which bases on the requirements of study and both students and lecturers can organize learning educational system storage, educational disposal storage as well as work platform to innovate new educational software mode and new textbook editing idea. The characters of teaching accumulations are:

1) the accumulations are not related to educational ideas, methods, or studying theories;

2) the accumulations are not related to textbook edition;

3) the accumulations are suitable for any changeable teaching phenomena.

In current condition, there is no unified national standard of educational accumulations and universities should establish some small accumulations database to collecting useful texts, graphics, animations, videos, audios, and other tools for lecturers choose[3]. The lecturers only need some basic software tools and they are able to create coursewares which match their teaching requirements. Those coursewares with strong characters only are used for individuals and will not bring any inconvenient for others. During the usage, the individuals will enrich them. Some adequate and practical personal courseware can be packed and uploaded to college websites or copied into $\mathrm{CD}$ for in-class use. Building educational accumulations is the future of courseware's development. On the one hand, they reduce the difficulties of non-computer lecturers' workload and make courseware designing as common as teaching-plan writing. Modifying courseware with different teaching condition becomes easy and rational which provide bright future for multimedia teaching system. On the other hand, they avoid redevelopment of courseware which continuously support computer assistant system and overcome the characterized obstacles. It is no doubt that human resources and materials supports are involved in accumulation storage construction. The best choice is start from part of main courses and extends to other courses later.

\section{CONCLUSION}

To correctly understand multimedia and its educational method, we should not only fully utilize it but also overcome superstition. We should notice that multimedia should be used as a teaching assistant tool, a new method and strategy. The e-education mode also needs us to improve and to consummate. In this case, students will receive the priority of it and it will show its valuable price in educational field. Thus, multimedia teaching method should base on the characters of teaching targets and objects during educational process through studying design, reasonable selecting and utilizing teaching medium, combining traditional teaching form, and performing a rational teaching process structure to reach the best effects of study. 


\section{REFERENCES}

[1] Han Shengjuan, "The Construction and Supervision of Multi -target Evaluation System of College Multi -media Teaching Quality", Education and Teaching Research, vol27,June.2013, pp.74-76.

[2] Zhou Yijun, Wang Chuanli, and Li Xuebin, "Research on quality monitoring system of multimedia teaching in colleges and universities", Journal of Anhui University of Science and Technology, vol14, Jan.2012,pp.77-80.

[3] Liu Hui,Huang Wulan, and Yan Mi, "Research on the Problems and Solutions of Constructing Multimedia Teaching Resource in College", Higher Education Forum,Jan.2012,pp.82-84. 